\title{
An infectious disease and pharmacokinetic perspective on oral antibiotic treatment of uncomplicated urinary tract infections due to multidrug-resistant Gram-negative uropathogens: the importance of urinary antibiotic concentrations and urinary $\mathrm{pH}$
}

\author{
B. A. Cunha ${ }^{1,2}$ \\ Received: 16 December 2015 / Accepted: 4 January 2016 /Published online: 9 February 2016 \\ (C) Springer-Verlag Berlin Heidelberg 2016
}

\section{Introduction}

One of the most common reasons for infectious disease consultation for urinary tract infections (UTIs) from urologists is regarding the selection of antibiotic therapy for acute uncomplicated cystitis (AUC) or catheter-associated bacteriuria (CAB) due to multidrug-resistant (MDR) Gram-negative bacillary (GNB) uropathogens in hospitalized and ambulatory patients. The important therapeutic decisions for AUC or $\mathrm{CAB}$ due to MDR uropathogens are regarding the interpretation of susceptibility testing, i.e., in vitro susceptibility versus in vivo effectiveness, and the choice of oral versus intravenous antibiotic therapy. This commentary is based on my experience and pharmacokinetic (PK) principles. The importance of urinary antibiotic concentrations in determining the urinary spectrum of oral antibiotics and the effect of urinary $\mathrm{pH}$ are discussed as determinants of therapeutic efficacy.

Effective antibiotic therapy of AUC due to MDR GNB uropathogens depends on several factors, e.g., the inherent activity of the antibiotic against the uropathogen, absolute versus relative resistance, achievable urinary antibiotic concentrations (largely determined by renal function), and the effect of urinary $\mathrm{pH}$ on both bacterial multiplication and antimicrobial activity. In normal hosts with effective antibiotic therapy of AUC, bacteriuria is rapidly eliminated in 6-12 h. In both normal and compromised hosts, the therapeutic

B. A. Cunha

bacunha@winthrop.org

1 Infectious Disease Division, Winthrop-University Hospital, 222 Station Plaza North (Suite \#432), Mineola, NY 11501, USA

2 School of Medicine, State University of New York, Stony Brook, NY, USA approach is the same, but in compromised hosts, rapidity of response, i.e., time to negative culture (TTNC), may be delayed and duration of therapy may need to be extended.

\section{Antibiotic urinary spectrum}

Stamey was the first to advance the concept of urinary (vs. serum) antibiotic spectrum [1]. Clinically, it is important to appreciate that in vitro antibiotic susceptibility testing is based on achievable serum, not urinary, antibiotic concentrations. Furthermore, serum susceptibility testing is done in broth at a serum $\mathrm{pH}$ of 7.4, not human urine at urinary $\mathrm{pH}$. Urinary antibiotic susceptibilities often differ considerably from serum susceptibilities [2-6]. Stamey reported that oral penicillin, due to high achievable urinary concentrations, easily eradicated Escherichia coli in urine, even though the E. coli was "resistant" by serum-derived susceptibilities [1, 4]. Stamey and others also showed that oral tetracycline, e.g., doxycycline, was effective in eradicating "tetracycline-resistant" Pseudomonas aeruginosa from urine. The minimum inhibitory concentration (MIC) of $P$. aeruginosa to tetracycline is $150 \mathrm{mcg} / \mathrm{ml}$, a level which is not achievable in serum at any dose. However, with intact renal function, urinary tetracycline levels are $>300$ $\mathrm{mcg} / \mathrm{ml}$, well in excess of the MIC of $P$. aeruginosa $[5,6]$.

Uropathogen susceptibilities reported as "susceptible" even though based on serum susceptibilities are accurate and clinicians can rely on this interpretation and expect elimination of bacteriuria by the antibiotic [4-10]. If the antibiotic has inherent activity against the uropathogen, but the uropathogen is reported as "resistant" or "non-susceptible" by serum susceptibility testings, then the organism may, in fact, be "susceptible" in urine if urinary levels exceed the MIC of the organism; against $E$. coli in urine, oral amoxicillin is more effective than the same dose of oral ampicillin since 
achievable urinary concentrations of amoxicillin greatly exceed those of ampicillin [11] (Table 1).

\section{Antibiotic relative and absolute resistance of MDR Gram-negative organisms in urine}

Antibiotic resistance makes therapeutic considerations complex $[12,13]$. Natural absolute/high-level resistance refers to resistance beyond the spectrum of the antibiotic, independent of antibiotic concentrations, e.g., enterococci are naturally cephalosporin-resistant. Acquired absolute/high-level resistance also cannot be overcome, regardless of achievable antibiotic concentrations. Acquired "relative resistance" refers to resistance that is concentration-dependent, e.g., doxycycline-"resistant" P. aeruginosa $(\mathrm{MIC}=150 \mathrm{mcg} / \mathrm{ml}$ ) is easily eradicated from urine, but not serum with oral doxycycline, since urinary levels are greater than the MIC (urinary level $=300 \mathrm{mcg} / \mathrm{ml}$ ) of the uropathogen $[5,6]$. To be effective against "resistant" uropathogens by serum susceptibility testing, urinary concentrations of the antibiotic must exceed the MIC of the uropathogen $[5,7,10]$. However, if the uropathogen is an extended-spectrum beta-lactamase (ESBL)-producing organism, e.g., E. coli and Enterobacter cloacae, urinary concentration aside, the antibiotic selected must have inherent activity against ESBL-positive organisms, e.g., IV: carbapenems, aminoglycosides; PO: nitrofurantoin, fosfomycin. Antibiotics inactivated by ESBLs will be ineffective against such organisms, regardless of urinary antibiotic concentrations [14, 15]. In addition, clinicians should be aware of the differences between in vitro susceptibility and in vivo effectiveness of certain antibiotics, e.g., Klebsiella pneumoniae is usually reported as susceptible to trimethoprim-sulfamethoxazole (TMP-SMX) but is often clinically ineffective against this particular pathogen [15]. Other factors being equal, subinhibitory or low concentrations of antibiotics near or below the MIC predisposes to resistance [12, 13]. Resistance is less likely with high antibiotic concentrations since susceptibility is, in part, concentration0dependent [16]. For this reason, in vitro serum susceptibility data overestimate the resistance of urinary isolates in the presence of high urinary antibiotic levels [7-11, 17, 18].

\section{The effect of urinary pH on the therapy of uncomplicated UTIs}

After high urinary concentrations, which determine the antibiotic urinary spectrum, urinary $\mathrm{pH}$ is the most overlooked factor potentially affecting the therapeutic response and TTNC. Urinary $\mathrm{pH}$ not only affects uropathogen growth, but it also affects the antimicrobial activity of several antibiotics [19-22]. Spectrum is, in part, pH-dependent with some antibiotics. The spectrum of erythromycin in an acid urine is limited to anti-enterococcal activity, but in an alkaline urine, erythromycin has activity against several GNB uropathogens [20]. For some antibiotics, antibiotic activity is heavily $\mathrm{pH}-$ dependent $[18,22]$. Some antibiotics have optimal antimicrobial activity in an acid urine $(\mathrm{pH}=5-6)$, e.g., cephalosporins, but these antibiotics have decreased antibacterial activity in an alkaline urine $(\mathrm{pH}>6)$. Similarly, antibiotics with optimal activity in an alkaline urine, e.g., erythromycin, have decreased activity in an acid urine $(\mathrm{pH}=5-6)$. The antimicrobial effect of some antibiotics is completely dependent on the urinary $\mathrm{pH}$, e.g., methenamine salts. Methenamine salts, in the presence of an acid urine, form formaldehyde, which is responsible for its antibacterial effects (Table 2). Furthermore, if the urinary $\mathrm{pH}$ decreases the activity of the antibiotic being used, it may have the same effect as subinhibitory urinary concentrations and may predispose to resistance [21].

The complexity of the effects of urinary $\mathrm{pH}$ is well illustrated with nitrofurantoin. Not only is the antimicrobial activity of nitrofurantoin $\mathrm{pH}$-dependent, but the tubular reabsorption of nitrofurantoin is $\mathrm{pH}$-dependent, e.g., an acid urine $(\mathrm{pH}=5-6)$ resulting in increased tubular reabsorption with renal, but lower, urinary concentrations. Since nitrofurantoin antimicrobial activity is optimal in an acid urine, the urinary $\mathrm{pH}$ may be as important as urinary concentrations in determining the efficacy of nitrofurantoin [23] (Table 3).
Table 1 Susceptibilities of "ampicillin-resistant Escherichia coli" tested in broth at serum $\mathrm{pH}$ compared to human urine at achievable urinary concentrations and urinary $\mathrm{pH}$

\begin{tabular}{|c|c|c|c|c|}
\hline \multirow[t]{2}{*}{ Oral antibiotics ${ }^{\mathrm{a}}$} & \multicolumn{2}{|l|}{ Broth at $\mathrm{pH} 7.4$} & \multicolumn{2}{|c|}{ Urine $^{\mathrm{b}}$ at $\mathrm{pH} 6.0$} \\
\hline & $\%$ Susceptible & $\%$ Resistant & $\%$ Susceptible & $\%$ Resistant \\
\hline Ampicillin & $0 \%(0 / 25)$ & $100 \%(25 / 25)$ & $64 \%(16 / 25)$ & $36 \%(9 / 25)$ \\
\hline Amoxicillin & $28 \%(7 / 25)$ & $72 \%(18 / 25)$ & $100 \%(25 / 25)$ & $0 \%(0 / 25)$ \\
\hline Doxycycline & $40 \%(10 / 25)$ & $60 \%(15 / 25)$ & $76 \%(19 / 25)$ & $24 \%(6 / 25)$ \\
\hline
\end{tabular}


Table 2 The effects of urinary $\mathrm{pH}$ on antibiotic activity in urine

\begin{tabular}{ll}
\hline Urinary $\mathrm{pH}$ & Oral antibiotics \\
\hline $\begin{array}{l}\text { Antimicrobial activity increased } \\
\text { with an acid urine }(\mathrm{pH}=5-6)\end{array}$ & $\begin{array}{l}\text { Ampicillin } \\
\text { Cephalosporins } \\
\text { Nitrofurantoin } \\
\text { Doxycycline } \\
\text { Fosfomycin }\end{array}$ \\
& Erythromycin \\
Antimicrobial activity increased & Quinolones \\
with an alkaline urine $(\mathrm{pH}>6)$ & TMP-SMX \\
& Methenamine \\
Antimicrobial activity requires & mandelate/hippurate \\
an acid urine (pH $=5-6)$ & (methenamine salts) \\
Antimicrobial activity unaffected & Amoxicillin \\
by urinary $\mathrm{pH}$ & \\
\hline
\end{tabular}

TMP-SMX trimethoprim-sulfamethoxazole

Adapted from $[18,22]$

\section{Oral antibiotic therapy of AUC due to MDR Gram-negative uropathogens}

There are many antibiotics available to treat GNB uropathogens. Problematic for many practitioners is the treatment of MDR GNB uropathogens in the hospital or ambulatory setting. Ordinarily, treatment of AUC should be via the oral route [15]. Physicians often resort to intravenous (IV) therapy for MDR GNB uropathogens, if not familiar with oral antibiotics that are effective against MDR GNB uropathogens [24-27]. The most important clinical considerations in selecting therapy for MDR GNB uropathogens is evaluation of the significance of achievable urinary concentrations, i.e., urinary spectrum, and the effect of urine $\mathrm{pH}$ on antimicrobial activity [25, 26]. IV therapy, which is not more effective than well-selected oral therapy, is problematic, i.e., requires IV access and prolongs hospital length of stay (LOS). In the outpatient setting, IV therapy has its limitations and is less convenient for the patient than oral antibiotic therapy [27]. For susceptible uropathogens, several oral antibiotics are available, e.g., cephalosporins and quinolones [15]. Even if the uropathogen is reported as "susceptible", it is necessary to select an antibiotic that is not only susceptible against the

Table 3 Nitrofurantoin: effects of urinary $\mathrm{pH}$ on urinary tract concentrations and antimicrobial antibiotic activity

\begin{tabular}{llll}
\hline & $\begin{array}{l}\text { Renal } \\
\text { concentration }\end{array}$ & $\begin{array}{l}\text { Urine } \\
\text { concentration }\end{array}$ & $\begin{array}{l}\text { Antimicrobial } \\
\text { activity }^{\mathrm{a}}\end{array}$ \\
\hline $\begin{array}{llll}\text { Alkaline urine }(\mathrm{pH}>6) \\
\begin{array}{l}\text { Acidic urine } \\
(\mathrm{pH}=5-6)\end{array}\end{array}$ & + & +++ & ++ \\
\hline
\end{tabular}

${ }^{\text {a }}$ Against susceptible uropathogens

Adapted from [23] uropathogen, but also will not induce widespread resistance in the hospital or community. Clinicians should preferentially select antibiotics with a "low resistance potential", i.e., resistance unlikely even with extensive antibiotic use, e.g., nitrofurantoin, levofloxacin, doxycycline. In contrast, "high resistance potential" antibiotics often predispose to resistance even with limited use, e.g., ciprofloxacin [12, 13, 15, 25] (Table 4). Clearly, the three most useful, "low resistance potential" oral antibiotics ideal for the treatment of MDR GNB uropathogens are nitrofurantoin, doxycycline, and fosfomycin $[15,25,28-36]$. These "low resistance potential" antibiotics are well tolerated and, properly used, have a good safety profile [15]. As with other antibiotics, optimal effectiveness is dependent on adequate renal function $(\mathrm{CrCl}>30 \mathrm{ml} / \mathrm{min})$, i.e., to achieve therapeutic urine levels ensuring effective urinary spectrum $[15,18,25,37]$. Although it is commonly thought that nitrofurantoin should not be used with creatinine clearances $(\mathrm{CrCl})<60 \mathrm{ml} / \mathrm{min}$, nitrofurantoin is effective if renal function is adequate, i.e., $\mathrm{CrCl} \geq 30 \mathrm{ml} / \mathrm{min}[15,25$, 30]. Ordinarily, $\mathrm{CAB}$ in normal hosts should not be treated. In compromised hosts, $\mathrm{CAB}$ presumptive treatment is prudent since urosepsis may result from bacteriuria, even with relatively low colony counts.

\section{Oral antibiotic therapy of CAB due to MDR Gram-negative uropathogens}

Except for the urinary catheter, the principles of antibiotic treatment of $\mathrm{CAB}$ is the same as for AUC, i.e., inherent antibiotic activity against the uropathogen, therapeutic urinary antibiotic concentrations, adequate renal function, as well as the effect of urinary $\mathrm{pH}$. The therapeutic problem presented by the indwelling urinary catheter, i.e., $\mathrm{CAB}$, is related to the catheter biofilm formed by the uropathogen $[2,30]$. Microorganisms become embedded in the catheter biofilm and cannot be easily eradicated by antibiotics. Antibiotics usually used for UTIs cannot penetrate the catheter biofilm to eliminate the uropathogen. Another common clinical problem is how to interpret urinalysis (UA) and urine culture (UC) in patients with indwelling catheters $[2,15,27]$. With indwelling urinary catheters, urine becomes colonized over time and pyuria is to be expected. With $\mathrm{CAB}$, high-level pyuria $(>50$ WBCs/ml) with high urinary colony counts (bacteriuria $>100 \mathrm{~K} / \mathrm{hpf}$ ) are indicative of colonization, not infection. Therefore, before "treating" CAB with antibiotics, first remove/replace the urinary catheter, then repeat the UA and UC. This intervention alone is curative, in most cases, since it removes the nidus of infection, i.e., the catheter biofilm. After urinary catheter removal/replacement, if pyuria and bacteriuria persist, treat as AUC as described $[15,30]$. 
Table 4 Antibiotic resistance potential

\begin{tabular}{|c|c|c|c|}
\hline \multicolumn{2}{|c|}{$\begin{array}{l}\text { Ciprofloxacin } \\
\text { (Organisms often resistant: E. coli) }\end{array}$} & \multicolumn{2}{|c|}{$\begin{array}{l}\text { Gentamicin or tobramycin } \\
\text { (Organisms often resistant: } P \text {. aeruginosa) }\end{array}$} \\
\hline \multicolumn{2}{|c|}{ TMP-SMX } & \multicolumn{2}{|c|}{ Ceftazidime } \\
\hline \multicolumn{2}{|c|}{ (Organisms often resistant: E. coli) } & \multicolumn{2}{|c|}{ (Organisms often resistant: P. aeruginosa) } \\
\hline \multicolumn{2}{|c|}{ Imipenem } & \multicolumn{2}{|l|}{ Ciprofloxacin } \\
\hline \multirow{3}{*}{\multicolumn{2}{|c|}{ (Organisms often resistant: $P$. aeruginosa) }} & \multicolumn{2}{|c|}{ (Organisms often resistant: E. coli) } \\
\hline & & \multirow{2}{*}{\multicolumn{2}{|c|}{$\begin{array}{l}\text { TMP-SMX } \\
\text { (Organisms often resistant: E. coli) }\end{array}$}} \\
\hline & & & \\
\hline \multicolumn{4}{|c|}{ "Low resistance potential" antibiotics (preferred antibiotics) } \\
\hline Meropenem & Levofloxacin & Doxycycline & Nitrofurantoin \\
\hline Amikacin & Aztreonam & Minocycline & Methenamine salts \\
\hline Ceftriaxone & Cefepime & Levofloxacin & Fosfomycin \\
\hline Piperacillin/tazobactam & Colistin & & \\
\hline Doxycycline & Tigecycline & & \\
\hline
\end{tabular}

TMP-SMX trimethoprim-sulfamethoxazole

Adapted from $[12,13,15]$

\section{Assessing antibiotic efficacy before urine culture results are reported}

With AUC, an antibiotic with inherent activity against the uropathogen is used in patients with adequate renal function, i.e., $\mathrm{CrCl}>30 \mathrm{ml} / \mathrm{min}$, and rapid elimination of the uropathogen ( $<3$ days) is expected [2,38]. Early in treatment, a useful way to predict subsequent eradication of bacteriuria is to obtain a UA after 2 days of therapy. A marked decrease in intensity of pyuria is, in my experience, predictive of subsequent cure, i.e., when UC results are later reported. After 2 days of therapy, if there is no decrease in pyuria intensity and with no marked decrease in urine colony counts, discontinue therapy and select another antibiotic. If there is substantially decreased pyuria after 2 days, therapy should be completed with the selected antibiotic, i.e., 3 days in normal hosts and 3-5 days in compromised hosts. After 2 days of therapy, if pyuria intensity is less and urinary colony counts are

Table 5 Pharmacokinetic and microbiological parameters of selected oral antibiotics useful in the therapy of multidrug-resistant (MDR) uropathogens

\begin{tabular}{|c|c|c|}
\hline Nitrofurantoin & Doxycycline & Fosfomycin \\
\hline Usual dose $=100 \mathrm{mg}$ & Usual dose $=100 \mathrm{mg}$ & Usual dose $=3 \mathrm{~g}$ \\
\hline Peak serum levels $=1 \mathrm{mcg} / \mathrm{ml}$ & Peak serum levels $=4 \mathrm{mcg} / \mathrm{ml}$ & Peak serum levels $=26 \mathrm{mcg} / \mathrm{ml}$ \\
\hline Serum half life $\left(\mathrm{t}_{1 / 2}\right)=0.5 \mathrm{~h}$ & Serum half life $\left(t_{1} / 2\right)=20 \mathrm{~h}$ & Serum half life $\left(\mathrm{t}_{1 / 2}\right)=5.7 \mathrm{~h}$ \\
\hline Bioavailability $=80 \%$ & Bioavailability $=93 \%$ & Bioavailability $=37 \%$ \\
\hline $\mathrm{PK}=$ concentration-dependant kinetics & $\mathrm{PK}=$ concentration-dependant kinetics & $\mathrm{PK}=$ concentration-dependant kinetics \\
\hline Excreted (unchanged) in the urine $=25 \%$ & Excreted (unchanged) in the urine $=48 \%$ & Excreted (unchanged) in the urine $=60 \%$ \\
\hline Urine levels $=100 \mathrm{mcg} / \mathrm{ml}^{\mathrm{a}}$ & Urine levels $=300 \mathrm{mcg} / \mathrm{ml}^{\mathrm{a}}$ & Urine levels $=1000 \mathrm{mcg} / \mathrm{ml}^{\mathrm{a}}$ \\
\hline Optimal urinary $\mathrm{pH}=$ acid urine $(\mathrm{pH}=5-6)$ & Optimal urinary $\mathrm{pH}=$ acid urine $(\mathrm{pH}=5-6)$ & Optimal urinary $\mathrm{pH}=$ acid urine $(\mathrm{pH}=5-6)$ \\
\hline Urinary spectrum & Urinary spectrum & Urinary spectrum \\
\hline E. coli $^{\mathrm{b}}$ & E. coli $^{\mathrm{b}}$ & E. coli $^{\mathrm{b}}$ \\
\hline Klebsiella sp. $^{\mathrm{c}}$ & Klebsiella sp. $^{\mathrm{c}}$ & Klebsiella sp. $^{\mathrm{c}}$ \\
\hline \multirow[t]{4}{*}{ Enterobacter sp. $^{\mathrm{c}}$} & Enterobacter sp. ${ }^{\mathrm{c}}$ & Enterobacter sp. ${ }^{\mathrm{c}}$ \\
\hline & Pseudomonas aeruginosa $^{\mathrm{c}}$ & Serratia marcescens ${ }^{\mathrm{c}}$ \\
\hline & & Proteus sp. \\
\hline & & Pseudomonas aeruginosa $^{\mathrm{c}}$ \\
\hline
\end{tabular}

\footnotetext{
${ }^{\mathrm{a}}$ With adequate renal function

${ }^{\mathrm{b}}$ Including ESBL-positive strains

${ }^{\mathrm{c}}$ Including MDR strains
} 
Table 6 Clinical approach to the therapy of MDR Gram-negative acute uncomplicated cystitis (AUC) based on the intensity of pyuria as a predictor of clinical response

Marked decrease in intensity of pyuria is predictive of eradication of bacteriuria (TTNC $<2$ days)

- Complete therapy with antibiotic selected

- Normal hosts: 3 days

- Compromised hosts: 3-5 days

No decrease in intensity of pyuria after 2 days is predictive of treatment failure

- Discontinue antibiotic

- Retreat with another antibiotic with inherent activity against the uropathogen that achieves high urinary concentrations

Mild to moderate decrease in intensity of pyuria is predictive of delayed eradication of bacteriuria (TTNC $>2$ days)

- If the antibiotic being used has optimal activity in an alkaline urine $(\mathrm{pH}>6)$ but the urinary $\mathrm{pH}$ is acid $(\mathrm{pH}=5-6)$, retreat with an antibiotic with optimal activity in an alkaline urine or alkalinize the urine (sodium bicarbonate)

- If the antibiotic has optimal activity in an acid urine $(\mathrm{pH}=5-6)$ but the urinary $\mathrm{pH}$ is alkaline $(\mathrm{pH}>6)$, retreat with an antibiotic with optimal activity in an acid urine or acidify the urine (ascorbic acid)

TTNC time to negative culture

decreasing, but bacteriuria persists, i.e., increased TTNC, then the clinician should consider the potential effect of urinary $\mathrm{pH}$ on antibiotic activity in urine. With effective antibiotic therapy for $\mathrm{AUC}$, bacteriuria (TTNC $=1-2$ days) rapidly clears. $\mathrm{CAB}$ due to MDR GNB uropathogens resistant to fosfomycin, at urinary concentrations and acid urinary $\mathrm{pH}$, after catheter replacement, therapy with methenamine salts are reliably effective if an acid $\mathrm{pH}$ is maintained $[15,18,37,39]$.

\section{Summary}

In conclusion, in normal hosts, AUC is easily treated using antibiotics to which the uropathogen is susceptible if renal function is adequate. Preferentially, use oral antibiotics with a "low resistance potential". For AUC due to MDR GNB, carefully select oral therapy, e.g., nitrofurantoin, doxycycline, or fosfomycin is as effective as IV therapy. The urinary spectrum of nitrofurantoin includes MDR GNB uropathogens (except Proteus sp., S. marcescens, P. aeruginosa) as well as vancomycin-susceptible enterococci (VSE) and vancomycinresistant enterococci (VRE). At urinary concentrations, doxycycline is active against most MDR GNBs, including $P$. aeruginosa. Fosfomycin has the same urinary spectrum as nitrofurantoin, but, in addition, is also active against Proteus sp., S. marcescens, and P. aeruginosa $[15,40]$ (Table 5). An effective clinical response may be assessed by repeat UA and UC after 2 days of therapy. Decreased intensity of pyuria is an early predictor of subsequent elimination of bacteriuria, i.e., negative urine culture. Unchanged pyuria intensity predicts therapeutic failure. The antibiotic should be stopped. After re-assessing the factors that determine therapeutic efficacy, i.e., achievable urinary concentrations and urinary $\mathrm{pH}$, the patient should be treated with another antibiotic. If there is a partial response to therapy, i.e., somewhat decreased pyuria and somewhat decreased urine colony counts, it is often the effect of an unfavorable urine $\mathrm{pH}$ on antibiotic activity and may be manifested by a prolonged TTNC. In such cases, there is delayed but eventual resolution of bacteriuria [39] (Table 6). Delayed or lack of response should prompt the clinician to reassess renal function, antibiotic urinary concentrations, and urinary $\mathrm{pH}$. Careful antibiotic selection, preferentially using "low resistance potential" antibiotics with an effective urinary spectrum, is critical to assure cure and to prevent resistance.

\section{Compliance with ethical standards}

Conflict of interest All authors declare there is no conflict of interest in the publication of this article.

\section{References}

1. Stamey TA, Govan DE, Palmer JM (1965) The localization and treatment of urinary tract infections: the role of bactericidal urine levels as opposed to serum levels. Medicine (Baltimore) 44:1-36

2. Doern GV, Brecher SM (2011) The clinical predictive value (or lack thereof) of the results of in vitro antimicrobial susceptibility tests. J Clin Microbiol 49:S11-S14

3. Washington JA 2nd (1983) Discrepancies between in vitro activity of and in vivo response to antimicrobial agents. Diagn Microbiol Infect Dis 1:25-31

4. Stamey TA, Fair WR, Timothy MM et al (1974) Serum versus urinary antimicrobial concentrations in cure of urinary-tract infections. N Engl J Med 291:1159-1163

5. Stamey TA (1972) Urinary infections. Williams \& Wilkins, Baltimore, pp 31-33, 253-269

6. Musher DM, Minuth JN, Thorsteinsson SB, Holmes T (1975) Effectiveness of achievable urinary concentrations of tetracyclines against "tetracycline-resistant" pathogenic bacteria. J Infect Dis 131:S40-S44

7. Cunha BA (2006) The clinical significance of resistant uropathogens in ambulatory urinary tract infections in women. Scand J Infect Dis 38:235-236

8. Hamid NS, Cunha BA, Klein NC (2005) Falsely high antibiotic resistance in community-acquired E. coli UTIs requiring hospitalization. Mayo Clin Proc 80:824-825

9. Cunha BA (1997) Problems arising in antimicrobial therapy due to false susceptibility testing. J Chemother 9:25-35

10. Cunha BA (2012) Predicting in vivo effectiveness from in vitro susceptibility: a step closer to performing testing of uropathogens in human urine. Scand J Infect Dis 44:714-715

11. Ristuccia PA, Cunha BA (1986) Activity of antimicrobial agents at urinary concentrations against ampicillin-resistant E. coli in human urine. Adv Ther 3:163-167 
12. Cunha BA (2000) Antibiotic resistance. Med Clin North Am 84: 1407-1429

13. Cunha BA (2001) Effective antibiotic-resistance control strategies. Lancet 357:1307-1308

14. Meier S, Weber R, Zbinden R, Ruef C, Hasse B (2011) Extendedspectrum $\beta$-lactamase-producing Gram-negative pathogens in community-acquired urinary tract infections: an increasing challenge for antimicrobial therapy. Infection 39:333-340

15. Cunha BA (ed) (2015) Antibiotic essentials, 14th edn. Jaypee Brothers Medical Publishers, New Delhi, pp 1-15, 103-106, 596-599, 619-620, 657-658

16. Cunha BA (2015) Tigecycline dosing is critical in preventing tigecycline resistance because relative resistance is, in part, concentration dependent. Clin Microbiol Infect 21:e39-e40

17. Klein Breteler KB, Rentenaar RJ, Verkaart G, Sturm PDJ (2011) Performance and clinical significance of direct antimicrobial susceptibility testing on urine from hospitalized patients. Scand J Infect Dis 43:771-776

18. Cunha BA, Comer JB (1979) Pharmacokinetic considerations in the treatment of urinary tract infections. Conn Med 43:347-353

19. Burian A, Erdogan Z, Jandrisits C, Zeitlinger M (2012) Impact of $\mathrm{pH}$ on activity of trimethoprim, fosfomycin, amikacin, colistin and ertapenem in human urine. Pharmacology 90:281-287

20. Lorian V, Sabath LD (1970) Effect of pH on the activity of erythromycin against 500 isolates of gram-negative bacilli. Appl Microbiol 20:754-756

21. Begic S, Worobec EA (2007) Fluoroquinolone resistance of Serratia marcescens: sucrose, salicylate, temperature, and $\mathrm{pH}$ induction of phenotypic resistance. Can J Microbiol 53:1239-1245

22. Yang L, Wang K, Li H, Denstedt JD, Cadieux PA (2014) The influence of urinary $\mathrm{pH}$ on antibiotic efficacy against bacterial uropathogens. Urology 84:713.e1-713.e7

23. Woodruff MW, Malvin RL, Thompson IM (1961) The renal transport of nitrofurantoin. Effect of acid-base balance upon its excretion. JAMA 175:1132-1135

24. Trevino SE, Babcock HM, Henderson JP et al (2015) Perceptions and behaviours of infectious diseases physicians when managing urinary tract infections due to MDR organisms. J Antimicrob Chemother 70:3397-3400

25. Cunha BA (2011) Multidrug-resistant Gram-negative bacilli causing urinary tract infections: clinical considerations. J Chemother 23: $171-174$

26. Frimodt-Møller N (2002) Correlation between pharmacokinetic/ pharmacodynamic parameters and efficacy for antibiotics in the treatment of urinary tract infection. Int J Antimicrob Agents 19: 546-553

27. Cunha BA (2006) Oral antibiotic therapy of serious systemic infections. Med Clin North Am 90:1197-1122

28. Garau J (2008) Other antimicrobials of interest in the era of extended-spectrum beta-lactamases: fosfomycin, nitrofurantoin and tigecycline. Clin Microbiol Infect 14:198-202

29. Komp Lindgren P, Klockars O, Malmberg C, Cars O (2015) Pharmacodynamic studies of nitrofurantoin against common uropathogens. J Antimicrob Chemother 70:1076-1082

30. Cunha BA, Schoch P, Hage JE (2012) Oral therapy of catheterassociated bacteriuria $(\mathrm{CAB})$ in the era of antibiotic resistance: nitrofurantoin revisited. J Chemother 24:122-124

31. Cunha BA, Domenico P, Cunha CB (2000) Pharmacodynamics of doxycycline. Clin Microbiol Infect Dis 6(5):270-273

32. Cunha BA (2012) Oral doxycycline for non-systemic urinary tract infections (UTIs) due to P. aeruginosa and other Gram negative uropathogens. Eur J Clin Microbiol Infect Dis 31:2865-2868

33. Greenwood D (1990) Fosfomycin trometamol: activity in vitro against urinary tract pathogens. Infection 18:S60-S64

34. Patel SS, Balfour JA, Bryson HM (1997) Fosfomycin tromethamine. A review of its antibacterial activity, pharmacokinetic properties and therapeutic efficacy as a single-dose oral treatment for acute uncomplicated lower urinary tract infections. Drugs 53:637-656

35. Bergan T, Thorsteinsson SB, Albini E (1993) Pharmacokinetic profile of fosfomycin trometamol. Chemotherapy 39:297-301

36. Liu HY, Lin HC, Lin YC, Yu SH, Wu WH, Lee YJ (2011) Antimicrobial susceptibilities of urinary extended-spectrum betalactamase-producing Escherichia coli and Klebsiella pneumoniae to fosfomycin and nitrofurantoin in a teaching hospital in Taiwan. $\mathrm{J}$ Microbiol Immunol Infect 44:364-368

37. Comer JB, Ristuccia PA, Digamon M, Cunha BA (1984) Antibiotic pharmacokinetics in urine. In: Ristuccia AM, Cunha BA (eds) Antimicrobial therapy. Raven Press, New York, pp 487-488

38. Jacobs MR (2003) How can we predict bacterial eradication? Int J Infect Dis 7:S13-S20

39. Cunha BA, Giuga J, Gerson S (2015) Predictors of ertapenem therapeutic efficacy in the treatment of urinary tract infections (UTIs) in hospitalized adults: the importance of renal insufficiency and urinary $\mathrm{pH}$ (submitted for publication)

40. Musher DM, Griffith DP (1974) Generation of formaldehyde from methenamine: effect of $\mathrm{pH}$ and concentration, and antibacterial effect. Antimicrob Agents Chemother 6:708-711 